\title{
Managerial Perceptions Concerning Nondisclosure of Sustainability Issues: A Case of Two Selected Banks in Bangladesh
}

\author{
Farid A. Sobhani ${ }^{1}$, Azlan Amran ${ }^{2}$
}

${ }^{1}$ Faculty of Business Studies, International Islamic University Chittagong, Bangladesh;

${ }^{2}$ Graduate School of Business, Universiti Sains Malaysia, Penang, Malaysia;

\begin{abstract}
This paper aims to explore the perceptions of senior bankers concerning nondisclosure of sustainability issues within the context of Bangladesh. The main objective of this paper is to critically examine the reasons for managerial reluctance to report corporate sustainability issues for two competing banks in Bangladesh, in general, and crucial issues, such as energy, human rights, and environmental issues, in particular. The study considered the perceptions of senior managers of two selected banks as gathered through an interview process. In total, 20 senior bankers of the two banks were interviewed to ascertain their perceptions concerning nondisclosure of corporate sustainability issues. The study found numerous reasons behind the nondisclosure of sustainability issues, such as the lack of sufficient resources, absence of the practice by other banks, lack of a legal framework, lack of pressure from any other concern, absence of a sustainable corporate plan, shortage of manpower, lack of infrastructure and logistic support, and the cost involved. From an institutional perspective, organizational changes are not always favourable, sometimes organizational actors adapt strategies to resist any change. This research provides an explanation for non-disclosed items in the two selected banks' sustainability reporting. The findings provide some indication of how such practices can be developed further.
\end{abstract}

Keywords: Sustainability issue, Nondisclosure, Banks, Institutional theory, Bangladesh.

JEL Classification Code: M49

\section{INTRODUCTION}

$\mathrm{T}$ HIS paper aims to explore the perceptions of senior bankers concerning nondisclosure of sustainability issues within the context of Bangladesh-an Asian nation. The main objective of this paper is to critically examine the reasons for managerial reluctance to report corporate sustainability issues for two banks in Bangladesh, in general, and crucial issues, such as energy, human rights, and environmental issues, in particular. A traditional and an Islamic bank have been selected to provide comparative views between two prominent banks under two competing financial systems in Bangladesh. Bangladesh has been selected as the location of this research on sustainability issues for three reasons: (a) Bangladesh is the first victim of global warming among the Asian countries, which is a crucial issue in the present world [1]; (b) To date, the publicly listed companies in the country have not produced any standalone sustainability report [2]; and (c) Banking companies seem to be the successful and dominant sector in the country [3], [4]. In addition, banks have been selected for three reasons. First, although the role of banks in sustainable socioeconomic development is globally recognized [5], banks lag in CSD research and, furthermore, Islamic banks are largely ignored and neglected [6]; second, banks can play a vital role in the socioeconomic development of a country [7], and, third, in respect of Bangladesh, various con- ventional and Islamic banks render substantial voluntary services for the sustainable development of the country [8].

Sustainability is a vital issue for a country like Bangladesh. It includes many issues relating to the economy, energy, natural environment, community development, human resources development, human rights, product responsibility, and corporate governance [5], [9], [10]. Not all issues are equally important to sustainable development. The degree of importance varies from country to country. In Bangladesh, energy, human rights, and environmental issues are "crucial" for its sustainable development. However, these issues are generally neglected by the corporate bodies in disclosure practices [2], [8], [11]. The power supply shortage, including gas and electricity, is the most vital sustainability issue in Bangladesh. The production of electricity depends on gas, however, the shortage of gas hampers electricity production, which causes many problems in society [12]. Environmental pollution is considered to be one of the key national challenges and concern has been expressed by many researchers that Bangladesh runs the risk of facing an "ecological catastrophe" if nothing is done to prevent it [2], [8], [13], [14]. In addition, many of the industrial units located on the banks of the Buriganga (main river of Dhaka, the capital city), Karnaphuli (main river of Chit- 
tagong, the port city) and other rivers are accused of polluting the rivers every day. This deprives the indigenous population of access to clean water and livelihoods that are based predominantly on fishing and boating activities [15] cited in [16].

As stated by Douglas et al. [7], financial institutions, especially banks, can play a "catalytic role" in changing the corporate behaviour of other industries towards sustainability management and disclosure. The disclosure of sustainability issues by the corporations does not have the potential to save any nation or planet [17], [18]. However, an explanatory study on such an issue on two leading banks can provide a comparative picture, develop awareness and enhance competition in the corporate world regarding sustainability practices and disclosure. Above all, this research initiative may help develop ways to protect the society, economy and environment. This paper proceeds with the background for the study by outlining the context of Bangladesh with specific regard to the crucial sustainability issues within this context. The next section of the paper provides a review of the prior literature before considering the research procedures adopted for the collection of data. In contrast to many previous CSD studies, this research documents the perceptions of senior bankers gathered through an interview process. Therefore, the paper addresses such empirical works by presenting and analysing the interview findings. The paper then presents the findings and theoretical discussion, and concludes with some analytical comments.

\section{Literature ReVIeW}

Corporate Sustainability Disclosure (CSD) is an emerging area of research [17], [19]. The Global Reporting Initiative (GRI) defined CSD as "the practice of measuring, disclosing, and being accountable to internal and external stakeholders for organizational performance towards the goal of sustainable development" [10, p.3]. Although the notion of sustainability was introduced during the 1990s, the issue of sustainability reporting and disclosure emerged in the early 2000s [17]. Since its emergence, the literature on sustainability disclosure has grown enormously. Prior research on sustainability issues mainly highlighted three things, first, the overall practices of corporate social and environmental disclosure [2], [7], [8], [20], [21], [22], [23], [24], [25], [26]; second, association between disclosure and possible determinants [27], [28], [29], [30] and third, managerial perceptions concerning corporate social and environmental disclosure (CSED) [16], [31], [32]. The nondisclosure of sustainability information is a common phenomenon for Asian developing countries such as Bangladesh. According to Belal [31], most of the social responsibility issues are not disclosed by listed companies in Bangladesh. Sobhani et al. [2] reported that $69 \%$ of the social and environmental information in the banking industry remains undisclosed.

No specific study has been found that addresses the rea- sons behind the nondisclosure of corporate sustainability issues. According to UNEP-FI (2006), corporate managers, mostly in the developing countries, are unaware of the term "sustainability management and reporting (SMR)". UNEP-FI (2006) identified two reasons for this: the lack of knowledge of the issues (by the top management) and the lack of capacity to deal with these issues. Rahim (2008) investigated the attributes concerning the disclosure of occupational safety and health (OSH) in the annual reports of Malaysian companies. The study revealed that some companies did not disclose OSH information because of the lack of a legal requirement. In fact, many companies do not disclose any sustainability information.

Belal and Copper [11] conducted managerial interviews to identify the reasons behind corporate reluctance to report eco-justice issues such as child labour, equal opportunities and poverty alleviation in the textile and garments industry for 2001-2002. They found that the factors behind the nondisclosure of eco-justice issues are international buyers for garment industries; civil society and government regulations for manufacturing industries; global pressure for multinational companies and trade unions for Government owned enterprises. Since the study was somewhat general, the author suggested that further research should examine the absence of corporate social disclosure in an individual organizational setting.

A review of prior studies regarding CSD practices shows that banking institutions particularly commercial banks have been omitted from CSD research (for example, [11], [16], [24], [33], [34]). Worldwide, only a few studies have been conducted regarding the disclosure of social and environmental information in the banking industry. Based on the availability of literature, some prior studies have been reviewed, which are mostly related to the developing Asian nations. An empirical research was conducted by Hamid [35] on Malaysian conventional financial institutions to look at specific patterns in the theme of disclosure. The results showed that all the sample banks disclosed more product related information than other aspects of social information. The results also showed that size, age and listing status appear to significantly influence the disclosure practice. In addition, the profitability variable showed an insignificant relationship with CSR disclosure. The study did not mention anything about the issues of nondisclosure behind social information.

Tsang [36] conducted a longitudinal study covering 1986 to 1995 on the annual reports of 17 companies incorporated in the three industries listed on the Stock Exchange of Singapore. There were six banks out of the three industrial sectors: bank, food and beverage, and hotels. The study revealed that the disclosure of banking companies is relatively more than other companies. The banking companies mainly disclosed information on human resources and community involvement. The 
amount of information disclosed did not differ much among the sectoral companies. The disclosure in this study was mostly qualitative and bad news was never disclosed. Most of the information was usually scattered and presented in an unstructured manner. No study is available on sustainability disclosure in the banking companies in Bangladesh. Only a sectoral view was highlighted in a CSED study by Sobhani et al. [2], which indicated that the banking sector disclosed more social and environmental information at that time. According to them, banking companies disclosed $31 \%$ of items of CSED, however, $69 \%$ of items remained undisclosed, which indicates the need for further research behind the nondisclosure of social and environmental information in the banking companies.

No specific study is available on sustainability disclosure in the arena of Islamic banks. A good number of studies have highlighted the disclosure (mainly financial reporting) of Islamic organisations and most of them proposed conceptual frameworks and hypothetical remarks. Baydoun and Willet [37] assumed that the accounting system in an Islamic society advocates more transparency, less conservative measurement practices and greater variability in disclosure practices between companies and across time. Sulaiman and Latiff [38] proposed a corporate reporting model for Islamic financial institutions. They also examined the annual reports of Islamic financial institutions in Malaysia and other Muslim countries including Pakistan, Bahrain and Turkey in order to investigate whether a gap exists between the 'desirable' and the 'actual'. Although the paper concluded that the corporate reporting of Islamic financial institutions, including banks, should be about how the individual (and more specifically the accountant) discharges the task of social accountability before God, it was mostly related to corporate financial performance. It was suggested by Sulaiman [39] that a comprehensive Islamic corporate report should comprise the traditional financial statements (balance sheet, income statement and cash flow statement), the current value balance sheet, a value added statement and the reporting of social and environmental issues.

A few empirical studies have been conducted to determine the extent of disclosure practices of Islamic financial institutions including Islamic banks. Haniffa and Hudaib [6] conducted a study in a move towards an appreciation of this neglected but important area by reporting on a survey of the annual reports of five Islamic financial institutions in four countries in the gulf region. The study aimed to gain insights into the variety and extent of disclosure and critically appraise various dimensions in these annual reports to contribute to a critique of disclosure practices in the context of Shari'ah (legal framework of Islam). The findings indicated that current disclosure practices are minimal, lack clarity and are inconsistent. The study was related to the overall corporate disclosure practices of Islamic financial institutions rather than discussing the CSD practices of Islamic banks.
In considering the lessons from the western reporting practices, Ibrahim and Yaya [40] studied the future of Islamic corporate reporting. This study aimed to elaborate upon the development of such practices and discussed their application as the vehicle in developing Islamic corporate reporting for any Muslim business organization and, particularly, for Islamic Banks. The study encouraged the development of social and environmental reporting practices in Muslim business organizations in addition to Shar'iah compliance reporting. Furthermore, in the future, it can be expected that learning from the development of social and environmental accounting in the West, Muslim business organizations will be accustomed to wider accountability than just to the shareholders, as is currently being practiced. In fact, the expectation of Ibrahim and Yaya [40] needs further research on Islamic banks to identify their current reporting practices, especially regarding social and environmental disclosure. From the above discussion, it is clear that no study is available on the sustainability of disclosure practices between an Islamic and a traditional bank, which provides a wide scope for contribution in the existing body of literature in the field of sustainability accounting. Indeed, conventional and Islamic banking systems are competing throughout the world. However, there are many differences between these two systems. The Islamic banking systems are guided by the principles of Islam and Shari'ah (legal framework of Islam). The main philosophy of doing business under the Islamic banking system is based on the profit sharing method instead of taking and giving interest, as interest (Riba) is strictly prohibited in Islam. Islamic banks are of a different nature in view of their established philosophies and operational activities, which differ from that of conventional banks [3], [39]. Because of the differences in philosophy and operations between Islamic and traditional banks, accounting and reporting practices also vary between these two rival systems. The main objective of a conventional accounting and reporting system is to satisfy the internal (e.g. loan providers, creditors, and investors) and external stakeholders (e.g. society, government etc.), while the Islamic accounting and reporting system considers accountability to almighty Allah as well as to internal and external stakeholders [39].

In view of the theoretical application, there is a lack of theoretical foundation in most of the research in the CSD arena, especially in developing countries. However, many theories have been espoused to explain the association between social and environmental disclosure and possible determinants. As noted by Larrinaga-Gonzalez [41], a good number of researchers applied NIS in their studies of sustainable management and reporting. The institutional theory was utilised by Hoffman [42] and Christmann [43] in their studies of corporate environmentalism, as well as by Jennings and Zandbergen [44] and Bansal [45] in their studies on sustainable organizations. Hoffman [42], for example, studied the evolution of 
environmentalism in the US Chemical Industry between 1962 and 1993 and found distinctive periods in terms of the institutionalization of environmental concerns. Kolk [46] studied the prevalence of environmental reporting by the Global Fortune 250 companies, including whether they are based in Europe, Japan or the US, and found that the region in which the MNC is based is significantly more important over time and that the differences in environmental reporting between the US and European/Japanese companies have increased over time. Crucially, in both of these studies, institutional elements were found to be active in causing a variation of environmental disclosure among the regions. Islam and Deegan [34] applied institutional theory to explain the motivational factors behind CSR reporting in Bangladesh. Sobhani et al. [2] posited that Institutional Theory, more specifically Neo-institutional Sociology (NIS) is suitable to interpret the CSD practices in the context of Bangladesh.

NIS is well known for the concept of isomorphism. The notion of "isomorphism" was highlighted as a central tendency towards homogeneity by DiMaggio and Powell [47]. They identified two types of isomorphism: competitive and institutional, in which competitive isomorphism arises from market forces and institutional isomorphism arises from the competition for political and organizational legitimacy. They focused on institutional isomorphism, identifying its three major mechanisms: coercive, mimetic and normative, which are properly placed and restructured by Scott under 'the three pillars of institutions'. The term "decoupling" or "loose coupling" is used by NIS to indicate a situation in which the organizational actors separate organizational activities from the formal structure [48]. In other words, it is a state of affairs in which the formal rules and procedures are not enforced in the organizational activities on a regular basis, but, instead, adopt different informal rules to suit the need of the business activities. NIS tackles the issue of loose coupling.

It is evident that NIS is mostly suitable in explaining managerial perceptions concerning nondisclosure of sustainability issues. According to NIS, organizations can resist institutional pressure in many ways. As explained by Scott [49], it is necessary to observe the extent to which institutional environments operate to influence and delimit what strategies organizations can deploy. Strategies that may be appropriate in one kind of industry or field may be prohibited in another. Oliver [50], however, primarily concentrates on the types of strategy that organizations can pursue irrespective of such field level constraints. She delineates five general strategies that are available to individual organizations confronted with institutional pressure:

- Acquiescence or conformity is the response that has received the lion's share of attention from institutional theorists.
- Compromise incorporates a family of responses that include balancing, placating, and negotiating institutional demands.

- The strategy of avoidance includes concealment efforts and attempts to buffer some parts of the organizations from the necessity of confronting the requirement.

- The strategy of defiance is one in which organizations not only resist organizational pressures to conform, but do so in a highly public manner.

- Organizations may respond to institutional pressures by attempting to manipulate - 'the purposeful and opportunistic attempt to co-opt, influence, or control the environment' [50, p. 157].

This study applied Neo-institutional Sociology (NIS) to explain the nondisclosure of crucial sustainability issues by the case banks in Bangladesh for several reasons. First, NIS possesses high explanatory power in comparison with other contemporary theories such as Stakeholder Theory and Legitimacy Theory [41]. Several notions of NIS including institutional resistance, isomorphism, decoupling and so forth remain lively concepts in the domain of organizational studies [50], [51], [52], [53], [54]. Notably, second, the theoretical concepts of NIS are pertinent to study the organizational phenomena in the context of CSD [2], [8]. Third, in addition to the multivariate application in other fields of accounting research, a trend has emerged to applying NIS frameworks in CSR and environmental accounting research [30], [34], [41]. Final$1 y$, according to Oliver [50] institutional theory provides a better framework in explaining managerial reluctance behind corporate disclosure.

\section{Methodology}

The study purposively selected two banks, the Sun and the Moon because of their extensive contribution in sustainable development. Two banks have been selected for comparative purposes. In any organization, the Managing Director (MD) or Chief Executive Officer (CEO), Additional Managing Director (AMD) or Deputy Managing Director (DMD), Corporate Secretary (CS), and Finance Director or Chief Finance Officer (CFO) [16], are considered key personnel of the top management. They are mostly aware of corporate affairs including social, environmental or sustainability disclosure. In total, 20 senior bankers of the two banks were interviewed to ascertain their perceptions concerning nondisclosure of corporate sustainability issues. In the case of the Sun, interviews with ten senior bankers, including the AMD, CFO, and $\mathrm{CS}$, and in the case of the Moon, interviews with ten senior bankers, including the CEO, DMD, CFO, and CS were considered. All the interviewees were highly qualified and experienced. Some of them were fellow members (FCA, FCMA) of national professional accounting bodies including the Institute of Chartered Accountants of Bangladesh. The identities of the interviewees have not been disclosed in this study to maintain confidentiality. 
The study used necessary codifications against interviews. For example, "InSn2" means "Interviewee of Sun 2 " and "InMn10" indicates "Interviewee of Moon 10". The duration of the interviews varied from 30 minutes to more than two hours depending on the degree of interest and the flow of discussion [31], [55]. The interviews took place at the interviewees' places of business during the periods March to July 2009 and December 2009 to January 2010.

The interviews were conducted in English and Bengali (local language) depending on the proficiency and style of speaking of the interviewees. Back-to-back translations of the interviews were made by a professional translator. The interview questions followed an ordinary guide as noted in the interview schedule. In most cases, the questions were asked in an open-ended fashion following a conversational style [16], [56]. Starting with the ordinary questions relating to the banking organization, personal affairs, the subsequent conversation broadly focused on the following targeted issue, that is, reasons behind the nondisclosure of sustainability issues. A semi-structured interview technique was used for the interviews [16], [31], [57]. The main reason behind such a technique was to remain critically engaged [57] in conversation in order to uncover the actual information regarding nondisclosure of sustainability issues. The key informants were the heads of the Accounts and Finance departments holding the position of Chief Accountant or Chief Finance Officer. In the case of the Sun, the corporate secretary and the bank foundation officials also gave important data and information about the CSD practices of their bank. A professional voice recorder was used to record the interviews with the consent of the respondents. Generally, the local language was used in the interviews and was translated into English to present in this study.

The transcription of the data took some time, as the researcher was required to listen to the tape a few times in order to ensure that all the conversation was transcribed properly. Prior to that, in the data analysis, the researcher listened to the tape more than once in order to familiarise themselves. During the listening, emerging or interesting points were noted. This initial process helped the researcher to be more prepared in investigating the subsequent respondents. The emerging pattern was observable from the initial analysis. The post interview analysis commenced immediately after the data collection process was completed. The average total transcription for each respondent was 6-7 pages ofA4, single spaced using Times New Roman characters font size 12. The transcripts for each respondent were then read more than once. This act was done simultaneously with the process of developing the big picture. It cannot be denied that there is some element of biasness when looking at the overall responses. This is explained by the constructivist approach in which the researcher normally looks at certain phenomenon from a certain perspective. The transcripts were than analysed thematically and interpreted through the lens of Institutional theory. The interview findings have been presented in the form of vignettes.

There were similarities in expression by some interviewees. For example, comments of most of the interviewees of the Moon were similar in nature. Hence, the comments deemed most appropriate are presented in this study. The findings of one interviewee were totally excluded from presentation. The reason behind the exclusion of the findings of an interview was because there was a significant gap between the two interviews with the same respondent of the Sun. During the first interview, the interviewee was found to be unaware of sustainability issues; however, during the second interview he deliberately expressed many issues about CSD practices. He talked extensively about his bank's CSR activities. In fact, the first interview made the executive aware of CSD issues, which is a good sign of awareness development. However, this type of awareness is not accepted in research, as it reduces data reliability.

\section{Findings}

Before presenting the interview findings, it is necessary to have a look at the case banks -the Sun and the Moon. "Sun" is the pseudonym for a conventional bank, which was established in 1996 as the first joint-venture bank in Bangladesh. Being a public limited company, it was listed on the Dhaka Stock Exchange in 2001 and with the Chittagong Stock Exchange in 1996. At the end of 2009, the deposit of the bank grew by 9,500 million Taka (local currency), which is equivalent to 136 million US dollars against the regulatory capital of 66 million US dollars (1 USD @ Taka 69). At present, the bank has more than 1,000 employees in its 80 branches and has its own training institute. The main focus of the bank is financing high-growth manufacturing industries in Bangladesh. The rationale being that the manufacturing sector exports Bangladeshi products worldwide. In respect of the modern banking services, the Sun claims to be the first automated bank in Bangladesh. The Electronic-Banking Division of the bank was established in 2002 to undertake rapid automation and bring modern banking services into this field. Full automation was completed in 2003 thereby introducing plastic money to the Bangladeshi masses. It also operates the nation's largest ATM network and has drastically cut consumer costs and fees by 80 percent. It is reported to have pursued mass automation in banking as a function of social responsibility.

The vision of the Sun is to have a better Bangladesh, where arts and letters, sports and athletics, music and entertainment, science and education, health and hygiene, a clean and pollution free environment, and, above all, a society based on morality and ethics that makes all lives worth living. Reportedly, its essence and ethos rest on a cosmos of creativity and the marvel-magic of a charmed life that abounds with the spirit of life and adventures that contribute towards human development. The mission of the bank is to fulfil customer needs with a 
commitment to social responsibility. The Sun established the "Bank Foundation", that is, with the name of the bank for social welfare activities in 1997, with an allocation from the annual profit of two and half percent $(2.5 \%)$ as the main source of funding. As reported, the sustainable focus of the bank is to promote Corporate Social Responsibility (CSR). The bank mainly performs sustainability activities under the caption of CSR in the annual report. The corporate website and newspapers are also an important medium of disclosure of the bank. The study found that because of its size and unique contribution to society, the bank is frequently referred to as the "CSR Bank" in Bangladesh. Factually, no other conventional bank is as socially involved as the Sun bank. It is the pioneer in this arena and termed the sustainable contribution simply as CSR. The annual report is the main avenue of disclosure practice of the bank followed by the website and newspapers. The areas of disclosure of the bank are related to social, economic, and environmental dimensions. The bank does not follow any international guidelines for reporting its CSR and sustainability activities [58].

Due to its investment in this sector it has become one of the biggest donors and the largest bank donor in the country. The bank won numerous national and international awards because of its operational performance and unique approach as a socially conscious bank. For instance, the bank received the Asian CSR Award in 2005, Best Annual Report Publication Award by the Institute of Chartered Accountants of Bangladesh (ICAB) in 2006, and was the winner of the 'Certificate of Merit' in the banking category based on published annual reports among South Asian Countries by the South Asian Federation of Accountants (SAFA) in 2007.

"Moon" is the pseudonym for an Islamic bank, which established the first interest-free bank as a public limited company in Bangladesh in 1983. It was listed with DSE in 1985 and with CSE in 1996, and was the first Islamic bank in the South East Asian region. The total equity of the bank stood at 18,572 million Taka, equivalent to USD 265 million, against the total paid up capital USD 70 million (1 USD @ Taka 70), as at the end of December 2009. The bank employed about 9,500 employees in its 206 branches, as at 31 December 2009.

The vision of the Moon is to establish and maintain modern banking techniques, to ensure the soundness and development of the Islamic financial system and to become a strong and efficient organization with highly motivated professionals working for the benefit of the people and society at large. It encourages savings in the form of direct investment. The mission of the bank is to establish Islamic banking through the introduction of a welfare oriented banking system and also ensure equity and justice in the field of all economic activities, achieve balanced growth, equitable and sustainable development through diversified investment operations, particularly in the priority sector and less developed areas of the country. It also targets to socioeconomically uplift and provide financial services to the low income community, particularly in the rural areas. In addition to the normal commercial and industrial investment operations, the bank has many special investment schemes related to social welfare and economic development.

The bank created a welfare fund named "Sadaqah Tahbil" to contribute to the socio-welfare activities in 1983. It was renamed as the "Bank Foundation" in the name of the bank in 1991. Zakat, donations, doubtful income of the bank (not free from interest), and income from the projects run by the Foundation are the main sources of income of the Foundation. Based on the corporate documentary publications including the annual report, it was found that the bank aims to render services to distressed people, orphanages, create employment opportunities for unemployed graduates, promote a technical and mass education system, help disaster victims through relief and rehabilitation programmes and keep the natural environment free from pollution. In addition to the annual report, the corporate website, newspapers, special publications on CSR activities, corporate brochures, and leaflets are the mediums of disclosure for corporate sustainability issues. The bank established a separate hospital under the same management to extend the health and medical services, especially to the poor. In addition to the welfare operations by the foundation and the hospital, the bank itself is directly involved with many social welfare activities.

The annual report is the main medium of disclosure practices of the Moon followed by the corporate website, brochures, magazines and newspapers [58]. The bank publishes a separate booklet on a regular basis highlighting its social welfare activities under the title "Welfare Programmes". It discloses many issues relating to the CSR and sustainability performance of the bank. The areas of disclosure of the Moon are related to social, economic, and environmental dimensions. Being an Islamic bank, it has to disclose a good number of issues concerning Riba (interest), Zakat (welfare fund for the poor), Quard Hasanah (benevolent funds), activities of Shari'ah council and so on. However, to make a fair comparison between the two case banks, the disclosure issues exclusively related to Islamic Dawah (invitation to God), principles, and practices as mentioned before have been excluded from the common instrument for content analysis. The bank does not follow any global reporting framework for disclosing corporate sustainability information.

Reportedly, the bank always strives to contribute to the society, economy and environment through superior financial services. It continuously strives to be the "number one" bank in the country through its operational performance and societal contribution. The bank has won many national and international awards because of its unique performance and contribution to socio-economic development. For instance, it received the "Best Bank Award" by the Global Finance, a reputable US based 
quarterly magazine, for the years 1999, 2000, 2004 and 2005. The Institute of Cost and Management Accountants of Bangladesh (ICMAB) awarded the bank the Best Corporate Award in 2007.

Being a conventional bank, the Sun is governed by secular banking laws, and is not influenced by religious principles or guidelines. In contrast, the Moon is of a different nature in view of its established philosophies and operational activities, which differ from that of the Sun. The Moon is guided by the principles of Islam and Shari'ah (legal framework of Islam). The philosophy of doing business under the Islamic banking system is based on the profit sharing method instead of taking and giving interest, as Interest (Riba) is strictly prohibited in Islam [3], [39].

It is evident from the above discussion that the two case banks are heterogeneous in nature in relation to their system, principles, and philosophies of business. According to Lounsbury and Crumley [59], heterogeneity in organizations leads to significant practice variations among them. Because of the differences in philosophy and operations between Islamic and traditional banks, accounting and reporting practices, the study posited that there would be a significant variation in managerial perceptions regarding the nondisclosure of sustainability practices between the Sun and the Moon. The findings of this study have helped investigate this theoretical proposition.

Regarding nondisclosure behind sustainability issues, the study found many reasons for the Sun and the Moon, which are separately presented for better understating. In the case of the Sun, two respondents opined that they did not feel the necessity to disclose all issues of sustainability performance.

Two other respondents pointed out that cost is a critical factor behind the nondisclosure of certain items of sustainability practices. One of the prominent bankers of the Sun mentioned that it is not wise to spend the additional amount on social welfare rather than spending on printing

Apart from the financial involvement, another respondent talked about the political cost which should be avoided. Disclosing all information to the Media may incur political cost.

An accountant argued that they published CSD issues based on their degree of importance and that not all items are of equal importance. :

Concerning the question of nondisclosure of eco-justice issues such as child labour and equal opportunity, the respondent rationalized the nondisclosure saying that none of the banks disclosed that information.

The concern of shareholders was pointed out by a respondent as a prime reason behind the nondisclosure of certain CSD information. He also mentioned that disclosure of sustainability information is as a voluntary issue which has no legal basis.

One of the top executives referred to the issue of legal requirements. He argued it is neither mandatory nor profitable and exclusively optional for a bank.

Likewise, another respondent highlighted the lack of necessary guidelines from the central bank as the reason behind the corporate unwillingness towards disclosure.

A prominent interviewee expressed that it would be impossible to disclose all information in the annual report and that they only disclose crucial CSD information on the corporate website and annual social report.

Similar to the Sun, the senior executives of the Moon were duly interviewed to identify the reasons behind the nondisclosure of certain items of sustainability practices. One of the respondents stated that he had no clear idea about this issue. Two of the respondents did not agree about the state of nondisclosure of the bank.

While their attention was drawn to the mostly ignored issues in disclosure, such as energy and human rights, one of them remained silent, while another responded with a counter question; do other banks disclose these types of information?

However, ultimately, the respondents agreed that energy, human rights, and climate change issues are vital for sustainable development in Bangladesh. All corporate bodies in Bangladesh should come forward in disclosing such crucial issues. According to them, the central bank or another corporate body should develop guidelines for the disclosure of energy, human rights, and climate change issues. They also emphasised a specific research to highlight the priority issues for CSR activities in Bangladesh.

Two respondents, including a top banker of the Moon, opined that the lack of motivation is the main reason behind the nondisclosure of certain sustainability issues. During the interview, a board member agreed that in previous years there were a number of items that remained undisclosed. He expressed the future plans of the bank to publish standalone social or sustainability reports each year electronically with adequate information on environmental and social welfare activities.

Another prominent banker stated that there is no actual reason behind the nondisclosure of important sustainability issues.

From the above findings, it is clear that there are multifaceted reasons behind the nondisclosure of crucial sustainability issues, which varies significantly between the conventional and Islamic bank. In the case of the Sun, the main reasons identified behind such nondisclosure include the lack of a legal framework, lack of practice by other banks, concern of shareholders, involvement in additional cost, and lack of pressure from any agency. In relation to the Moon, the study found that the lack of motivational force, absence of a sustainable corporate plan, absence of practice by other banks, scarcity of manpower, lack of infrastructure and logistic support, and involvement of cost are the main reasons behind the nondisclosure of certain items of CSD information. 


\section{Discussion \& CONCLUSION}

The question arises as to how acceptable are the reasons behind the corporate unwillingness to address the crucial sustainability issues such as energy, human rights, and environmental protective measures. The basis for nondisclosure is nothing more than a corporate dilemma. As a result, the respondents from both of the case banks pointed out many diverse issues behind such nondisclosure. In the context of Bangladesh, a recent study on the absence of corporate responsibility reporting was conducted by Belal and Cooper [11]. They highlighted the nondisclosure part of eco-justice issues such as child labour, equal opportunities, and poverty alleviation. The findings of this study also revealed the same eco-justice issues undisclosed except poverty alleviation. The Moon disclosed considerable information in its annual reports on poverty alleviation as the bank has different types of poverty alleviation schemes such as the rural development scheme, household durables scheme, small business investment scheme, and micro-industries investment scheme. However, the study identified other undisclosed crucial issues that mainly relate to energy, human rights, and the natural environment.

Prior studies particularly in Asian context identified a number of reasons behind the nondisclosure of corporate social information that are similar to the findings of this study. Belal and Cooper [11] identified three reasons behind the nondisclosure of eco-justice issues, which are the lack of legal requirements, lack of knowledge/awareness, poor performance and fear of bad publicity. The importance of cultural attitudes within a country was specifically reported as a reason for nondisclosure by Adams [20] - in the context of Thailand, this includes little pressure from community pressure groups, failure to enforce legislation, and the absence of mandatory social and environmental disclosure [60]. The importance of the absence of regulatory requirements was also noted by Adams et al. [61] and the same was identified as the prime reason for the lack of corporate social reporting in a Jordanian study [62].

Regarding commercial banks, Sobhani [63] found that certain issues of CSD, such as energy, human rights, and environmental items are less disclosed compared to other items of sustainability disclosure, which indicates organizational resistance behind the CSD practices. Energy is the most ignored theme among the CSD dimensions followed by human rights and environmental themes. Except for recent investment in energy projects, none of the case banks disclosed any other information about energy. As discussed in the local context, power crisis, environmental pollution, and violation of human rights are the longstanding crucial problems in Bangladesh. Considering these challenges, it was expected that the case banks would disclose adequate information concerning corporate attempts to raise public awareness and make institutions accountable to society. However, the disclosure scenario of these items was unexpected as mentioned earlier.

As reported before, there are a number of reasons behind the nondisclosure of crucial sustainability issues. Although the study found a significant variation in managerial perceptions in disclosure practices, the absence of the practice by other scheduled banks and lack of regulation are the common reasons for the nondisclosure by both case banks. The forces that could create isomorphism itself are not in place for the executives in the bank to feel it and act accordingly in their CSD. It is true for some sustainability issues, which do not receive attention from members in the industry even though they are important. It is clearly seen here that for non-disclosed items to be practiced, the institutional mechanism must first be in place. This explains why even though energy and human rights issues are important issues in Bangladesh they are not included in the reports of the two banks. The whole environment in which the two banks are operating does not see these issues as critical. This also implies that the awareness about the need to disclose such information is still low.

Change in practices frequently occurs due to cultural influences. Culture is a vital institution of culturalcognitive mechanism of NIS. Culture, defined by Hofstede [64] as "a collective mental programming" has been identified as an important variable for institutional change. Culture is often conceived of as a unitary system, internally consistent across groups and situations [49]. Institutional changes are widely connected to cultural values [65]. According to Lounsbury [66], cultural systems reflect the core of contemporary institutional theory or the new institutionalism. It shapes the reality of organisational life. The uniqueness of NIS is rooted in culture [67].

There is evidence that social and environmental disclosure is related to corporate culture and habit [27], [67], [68], [69]. Qu and Leung [68] demonstrated the impact of China's culture on disclosure practices and found that a new corporate culture had emerged. The Chinese listed companies were willing to provide voluntary information in addition to the disclosure requirements. Bloom and Solotko [70] reported that the Chinese culture has the potential to impact on their corporate social and environmental disclosure.

In relation to the case banks, the Sun developed a unique corporate culture in practising CSD activities in the banking industry in Bangladesh. It established a separate CSR department that is run by the bank foundation. As reported, the bank foundation performs CSR activities according to the annual plan of the bank. Later on, the foundation provides data and information on CSR performance to the accounts and finance department for the purpose of external disclosure by the bank. In the case of the Moon, a religious-based culture, which is different from the traditional corporate culture in Bangladesh, has emerged. Therefore, non-disclosure of crucial sustainability information seems to be a cultural issue too. 
The reasons behind nondisclosure may also be interpreted as resistance strategies to rationalize their arguments. To some extent, fear of negative sanctions or rejection of project clearance by the government authorities force the bank to comply, which is also a mode of compromise with the institutional requirements. Compromise is particularly likely to occur in environments containing conflicting authorities. Alexander [71] describes a combination of compromise strategies as being pursued by curators of fine arts museums in the United States. This implies that organizations will frequently find themselves in situations where they have considerable scope to negotiate and a declaration of compliance may help them avoid other instructional demands.

A basic premise of Oliver's [50] typology of strategic responses to institutional pressure is that corporate agents will resist threats to their autonomy or survival. Institutionalists express that politically powerful actors in a contested arena would resist any change whenever they realize that the change would undermine their survival, power, or autonomy (see [49], [50], [72], [73]). Resistance strategies in a particular organization depend on the capacity and role of corporate resisters. In fact, an analysis of the role of organizational actors, including resisters, along with the institutional links, is necessary to understand the overall institutionalization process in an organization. As stated by Lounsbury [67], organisational actors rationalise their action.

In the Sun, they seem to avoid disclosure of crucial sustainability items relating to energy, the environment and human rights themes. This is evident in the interview findings. As stated before, some of the respondents denied the importance of sustainability disclosure (see for example, InSn2,7 \& InMn3). This mode of avoidance is a strategy of resistance of neo-institutionalism, as explained by Scott [49]. Organizations confronting demands frequently respond by "decoupling" their formal features from their technical activities [74]. In the Sun, a credibility gap (loose coupling) is obvious between the practices and its disclosed statements in the annual reports.

Loose coupling among differentiated units is a characteristic feature of all organizations - indeed, of all open systems [48]. Organizations under pressure adopt particular procedures and may opt to respond in a ceremonial manner, making changes in their formal structures to signal conformity, but then buffering internal units, allowing them to operate independent of these pressures. Although this is certainly a possible response, Meyer and Rowan imply that this response is widespread [74]. Although some theorists consider decoupling as the hallmark of an institutional argument, Scott disagreed with this interpretation. According to him, the decoupled or loose-coupled responses are often seen to be merely symbolic. Organizations under certain conditions adopt requisite structures, but then fail to carry out the associated activities [49], [75]. According to Powell [75], it is difficult to rationalize the changes because of the institutionalization process if decoupling or loose coupling exists in the organization.

In addition to decoupling, the NIS recognizes that corporations act to rationalize their strategies to resist any unfavourable change. In respect of the institutional perspective, organizational changes are not always favourable; sometimes, organizational actors adapt strategies to resist any change (see [76]), as found in the Sun. The main reasons behind nondisclosure are seemingly managerial strategies to rationalize their steps to overlook important items of disclosure. The legal issue was mentioned several times by the respondents during interviews with both case banks. Although the case banks are heterogeneous in nature, a regulatory binding will help both case banks maintain similarity in disclosure practices. Therefore, in the context of Bangladesh, a legal requirement is essential to enhance the disclosure of crucial sustainability issues.

Even though the sustainability issues are crucial in the context of Bangladesh, the reasons behind nondisclosure are not explicit. Due to differences in institutional formation, organizational goals and objectives, corporate cultural and practices, there were differences in the managerial perceptions concerning nondisclosure of sustainability issues between the two banks. However, the absence of the practice by other scheduled banks and the lack of sufficient resources were the common reasons for the nondisclosure by both case banks. According to NIS, there is non-existence of institutional forces, as none of the three institutional mechanisms exist to pressure the case banks to disclose some of the non-disclosed items. To some extent, it is the whole environment that is not supportive of the two banks. In addition, from an institutional perspective corporations are perceived to rationalize their strategies to resist any unfavourable changes. Therefore, nondisclosure of corporate sustainability issues by the two banks is as strategy for resistance, which is reinforced by the non-existence of pressure on certain important issues.

\section{REFERENCES}

[1] S.N. Pasha, "Bangladesh must be saved, UK Parliament told. The BD News," Retrieved from www.bd news24.com on November 2009.

[2] F.A. Sobhani, A. Amran, and Y. Zainuddin, "Revisiting the corporate social and environmental practices in Bangladesh," Corporate Social Responsibility and Environmental Management, 16(3), pp.167-183, 2009.

[3] A. Raquib, "Principles and practices of Islamic Banking," Dhaka: Chowkash Printers, 2007.

[4] A.A. Sarker, "Regulation of Islamic Banking in Bangladesh: Role of Bangladesh Bank," International Journal of Islamic Financial Services, 2(1), pp. 46-46, 2000.

[5] UNEP-FI, "Sustainability management and reporting (benefits for financial institutions in developing and emerging economies). UNEP Finance Initiative," Retrieved from http://www.unepfi.org/about/index.html on August 10, 2008.

[6] R. Haniffa and M. Hudaib, "Disclosure practices of Islamic financial 
institutions: An exploratory study," Conference Proceedings, 2004: The International Conference on Accounting, Commerce \& Finance: The Islamic Perspective, Brisbane, Australia, 2004.

[7] A. Douglas, J. Doris and B. Johnson, "Corporate social reporting in Irish financial institutions," The TQM Magazine, 16(6), pp. 387-395, 2004.

[8] F.A. Sobhani, Y. Zainuddin and A. Amran, "Sustainability disclosure practices in Bangladesh: The case of banking industry," Proceedings from UWS'09: Sustainability Research Symposium. NSW, Australia: University of Western Sydney, 2009.

[9] ACCA, "Sustainability reporting guidelines for Malaysian companies," Malaysia: The Association of Chattered Certified Accountants, 2005

[10] GRI, "Sustainability Reporting Guidelines [G3]," Global Reporting Initiative (GRI), Amsterdam, 2006.

[11] A.R. Belal and S. Cooper, "The Absence of Corporate Social Responsibility Reporting in Bangladesh," Critical Perspectives on Accounting, 22(2), pp.183-199, 2011.

[12] M. Ret, "Water, energy and crisis in Bangladesh," Retrieved from: http:/ /libcom.org/news/water-energy-and-crisis-bangladesh07052007 on April 16, 2010.

[13] Global Environment Facility, "Community-based adaptation to climate change through coastal afforestation in Bangladesh, Retrieved from: www.theGEF.org on April 12, 2010.

[14] H. Inam, "Bangladesh faces threat of ecological catastrophe," The Bangladesh Observer, Dhaka: Bangladesh, 1995.

[15] A. Nurunnabi, "Pollution of river water," The Daily Star. Retrieved from www.dailystarnews.com on June 29, 2002.

[16] A.R. Belal and D.L. Owen, "The views of corporate managers on the current state of, and future prospects for, social reporting in Bangladesh - An engagement-based study," Accounting, Auditing and Accountability Journal, 20(3), pp. 472-494, 2007.

[17] N. Buhr, "Histories of and rationales for sustainability reporting," In J. Unerman, J. Bebbington, \& B. O'Dwyer (Eds.), Sustainability Accounting and Accountability (pp. 57-69). London and New York: Routledge, 2007.

[18] M. J. Milne and R. Gray, "Future prospects for corporate sustainability reporting," In J. Unerman, J. Bebbington, \& B. O'Dwyer (Eds.), Sustainability Accounting and Accountability (pp. 184-204). NY: Routledge, 2007.

[19] C. A. Adams and P. McNicholas, "Making a difference, sustainability reporting, accountability and organizational change," Accounting, Auditing and Accountability Journal, 20(3), pp. 382-402, 2007.

[20] C. A. Adams, "The ethical, social and environmental reportingperformance portrayal gap," Accounting, Auditing \& Accountability Journal, 17(5), pp.731-757, 2004.

[21] H. Ahmed, "Corporate voluntary reporting practices in India," The Cost and Management, 33(5), pp. 73-79, 2005.

[22] H. Ahmed, "Voluntary reporting practices in corporate annual reports: The case of Bangladesh," The Bangladesh Accountant, 4, 82-85, 2005.

[23] A.R. Belal, "Social and environmental disclosure in Bangladesh," The Cost and Management, 2, pp.10-14, 1999.

[24] A.R. Belal, "A study of corporate social disclosures in Bangladesh," Managerial Auditing Journal, 16(5), pp. 274-289, 2001.

[25] E. Chambers, W. C. J. Moon and M. Sullivan, "CSR in Asia: A Seven Country Study of CSR Website Reporting," Research Paper Series of the International Centre for Corporate Social Responsibility. Retrieved from

http://www.nottingham.ac.uk/business/ICCSR/pdf/Re searchPdfs/09-2003. on 8 November , 2008.

[26] H. Haron, D. N. Ibrahim, I. Ismail, Q. C. Hoo, N. N. K. Ali, Y. Zainud- din, E. Nasruddin, S.R. Saiful and H. Hariri, "Governance, ethics and corporate social responsibility of public listed companies in Malaysia," A report submitted to the Institut Integriti Malaysia and IIM-MAREF, Malaysia (unpublished), 2006.

[27] C. A. Adams, "Internal organizational factors influencing corporate social and ethical reporting: beyond current theorizing," Accounting, Auditing and Accountability Journal, 15(2), pp. 223-250, 2002.

[28] N.N.B.N. Ahmad, M. B. Sulaiman and D. Siswantoro, “Corporate social responsibility disclosure in Malaysia: An analysis of annual reports of KLSE listed companies," IIUM Journal of Economics and Management, 11(1), pp.1-37, 2003.

[29] A. Amran, "Corporate social reporting in Malaysia: An institutional perspective," An unpublished Doctoral Thesis, University of Malaya, Malaysia, 2006.

[30] A. Amran and S. S. Devi, "Corporate social reporting in Malaysia: An institutional perspective," World Review of Entrepreneurship, Management and Sustainable Development,3(1), pp. 20-36, 2007.

[31] A. R. Belal, "Corporate social responsibility reporting in developing countries: The case of Bangladesh," Ashgate:UK, 2008.

[32] B. O'Dwyer, "Managerial perceptions of corporate social disclosure: An Irish story," Accounting, Auditing and Accountability Journal, 15(3), pp. 406-436, 2002.

[33] S. Imam, "Corporate social performance reporting in Bangladesh," Managerial Auditing Journal, 15(3), pp. 133-141, 2000.

[34] M. A. Islam and C. Deegan, "Motivations for an organization within a developing country to report social responsibility information," Accounting, Auditing \& Accountability Journal, 21(6), pp. 850-874, 2008.

[35] F. Z. A. Hamid, "An empirical investigation of corporate social disclosure by banks and finance companies in Malaysia," International Journal of Scientific Management: Ownership and Control, 1(4), pp. 14-33, 2004.

[36] E. W. K. Tsang, "A longitudinal study of corporate social reporting in Singapore: The case of banking, food \& beverages and hotel industries," Accounting, Auditing and Accountability Journal, 11(3), pp. 624 35, 1998.

[37] N. Baydoun and R. Willet, “Islamic Corporate Reports," Abacus, 36(1), pp.71-90, 2000.

[38] M. Sulaiman and R. A. Latiff, "Corporate reporting of Islamic financial institutions: examining the gap between the "desirable" and the "actual"," Accounting, Commerce and Finance: The Islamic Perspective Journal. 9(2), pp. 61-94, 2005.

[39] M. Sulaiman, "Islamic corporate reporting-between the desirable and the desire (1st ed.)," International Islamic University Malaysia: Research Centre, 2005.

[40] S. H. M. Ibrahim and R. Yaya, "The Future of Islamic Corporate Reporting: Lessons from Alternative Western Accounting Reports," Paper presented in the International Conference on Quality Financial Reporting and Corporate Governance, IIUM, 2003.

[41] C. Larrinaga-Gonzalez, "Sustainability reporting-insights from neoinstitutional theory," In J. Unerman, J. Bebbington, \& B. O'Dwyer (Eds.), Sustainability Accounting and Accountability (pp. 151-167). London and New York: Routledge, 2007.

[42] A.J. Hoffman, "Institutional evolution and change: Environmentalism and the US chemical industry," Academy of Management Journal, 42(4), pp.351-371, 1999.

[43] P. Christmann, "Multinational companies and the natural environment: Determinants of global environmental policy standardization," Academy of Management Journal, 47(5), pp.747-760, 2004.

[44] P.D. Jennings and P.A. Zandbergen, "Ecologically sustainable organi- 
zations: An institutional approach," Academy of Management Review, 20(4), pp.1015-1052, 1995.

[45] P. Bansal, "Evolving sustainability: A longitudinal study of corporate sustainable development," Strategic Management Journal, 26, pp.197218, 2005.

[46] A. Kolk, "Trends in Sustainability Reporting by the Fortune Global 250," Business Strategy and the Environment, 12(5), pp.279-291, 2003.

[47] P.J. DiMaggio and W.W. Powell, "The iron case revisited: Institutional isomorphism and collective rationality in organizational fields," American Sociological Review, 48, pp.147-160, 1983.

[48] J.D. Orton and K.E. Weick, "Loosely coupled systems: a reconceptualization," Academic of Management Review, 15, pp.203-223, 1990.

[49] W. R. Scott, "Institutions and Organizations: Ideas and Interest (3rd Ed.)," Thousand Oaks, CA: Sage, 2008.

[50] C. Oliver, "Strategic responses to institutional processes," Academy of Management Review, 16(1), pp.145-169, 1991.

[51] Z. Hoque, "Securing institutional legitimacy or organizational effectiveness: A case examining the impact of public sector reform initiatives in an Australian Local Authority," International Journal of Public Sector Management, 18(4), pp. 367-382, 2005.

[52] I. Lapsley and J. Pallot, "Accounting, management and organizational change: A comparative study of local government," Management Accounting Research, 11, pp. 213-229, 2007.

[53] C. Oliver, "The antecedents of deinstitutionalization", Organization Studies, 13/4: pp. 563-588, 1992.

[54] W. H. White, "Inside institutional change: A case study in transformation," The Horizon, 13(1), pp. 54-58, 2005.

[55] R. J. Orr and W. R. Scott, "Institutional exceptions on global projects: a process model," Journal of International Business Studies, 39, pp. 562$588,2008$.

[56] R. Maykut and R. Morehouse, "Beginning Qualitative Research: A Philosophical and Practical Guide," London: The Falmer Press, 1994.

[57] R. Gray, "The social accounting project and Accounting, Organization and Society privileging engagement, imaginings, new accountings and pragmatisms over critique?" Accounting, Organization and Society, 27(7), pp. 687-708, 2002.

[58] F. A. Sobhani, Y. Zainuddin, A. Amran and A. Baten, “Corporate sustainability disclosure practices of selected banks: A trend analysis approach," African Journal of Business Management, 5(7), pp. 2794 2804, 2011.

[59] M. Lounsbury and E.T. Crumley, "New practice creation: an institutional perspective on innovation," Organization Studies, 28(07), pp. 993-1012, 2007.

[60] N. Kuasirikun, and M. Sherer, "Corporate social accounting disclosure in Thailand," Accounting, Auditing and Accountability Journal, 17(4), pp. 629-660, 2004.

[61] C.A. Adams, A. Coutts and G. Harte, "Corporate Equal Opportunities (Non-) Disclosure," British Accounting Review, 27(2), pp. 87-108, 1995.

[62] K. Naser and N. Baker, "Empirical Evidence on Corporate Social Responsibility Reporting and Accountability in Developing Countries: The Case of Jordan," Advances in International Accounting, 12, pp.193-226, 1999.

[63] F.A. Sobhani, "Sustainability disclosure practices of banks in Bangladesh: A case study from an institutional perspective," $\mathrm{PhD}$ thesis (work in progress), Universiti Sains Malaysia, 2010.

[64] G. Hofstede, “Culture's Consequences," Sage Publications, 1980.

[65] L.G. Zucker, "Institutional theories of organizations," Annual Review of Sociology, 13, pp. 443-464, 1987.

[66] M. Lounsbury, "Exploring the Institutional Toolkit: The Rise of Recy- cling in the U.S. Solid Waste Field," American Behavioral Scientist, 40, pp. 465-477, 1997.

[67] M. Lounsbury, "Institutional rationality and practice variation: New directions in the institutional analysis of practice," Accounting, Organizations and Society, 33, pp. 349-361, 2008.

[68] W. Qu and P. Leung, "Cultural impact on Chinese corporate disclosure-a corporate governance perspective," Managerial Auditing Journal; 21 (3), pp. 241-264, 2006.

[69] L.K. Williams, "How culture evolves: an institutional analysis," International Journal of Social Economics, 34(4), pp. 249-267, 2007.

[70] R. Bloom and J. Solotko, "The foundation of Confucianism in Chinese and Japanese Accounting," Accounting, Business \& Financial History, 13 (1), pp. 27-40, 2003.

[71] V. D. Alexander, "Pictures at an exhibition: Conflicting pressures in museums and the display of art," American Journal of Sociology, 101, pp. 797-839, 1996.

[72] P. J. DiMaggio, "Interest and agency in institutional theory," In L. G. Zucker (Ed.), Institutional Patterns and Organizations: Culture and Environment (p. 21). Cambridge, MA: Ballinger, 1988.

[73] W. R. Scott, “Institutions and Organizations (1st Ed.)," Thousand Oaks, CA: Sage, 1995.

[74] J. Meyer and B. Rowan, "Institutional organizations: formal structures as myths and ceremonies," American Journal of Sociology, 83(2), pp. 340-363, 1977.

[75] W.W. Powell, "Expanding the scope of institutional analysis," In W.W. Powell and P. J. DiMaggio (Eds.), The New Institutionalism in Organizational Analysis (pp.183-203), Chicago: The University of Chicago Press, 1991.

[76] B. Shapiro and D. Matson, "Strategies of resistance to internal control regulation," Accounting, Organizations and Society, 33 (2-3), pp.199$228,2007$. 